\title{
Review of Rethinking East-Central Europe: family systems and coresidence in the Polish Lithuanian Commonwealth edited by Szoltysek, Mikolaj
}

\author{
Aurora Angeli[D
}

Correspondence:

aurora.angeli@unibo.it

University of Bologna, Bologna, Italy

\section{Book details}

Szoltysek, Mikolaj. 2015.

Rethinking east-Central Europe: family systems and coresidence in the Polish Lithuanian Commonwealth.

Bern, Switzerland: Peter Lang. Vol. 1: contexts and analyses; Vol. 2: data quality assessments, documentation, and bibliography. 1062 pp. no. 21, ISBN 978-3-0351-9998-7 in the series entitled population, family, and society.

Mikolaj Szoltysek proposes a masterly and comprehensive analysis of family life in the Polish-Lithuanian Commonwealth (PLC) at the end of the eighteenth century. This ponderous book (over 1000 pages) is organized in two volumes: the first volume is devoted to the introduction to the studied areas and to the analyses, while the second volume includes data quality assessments, documentation, and bibliography.

Our attention will be devoted mostly to the first volume, which contains a discussion of family patterns, starting from the evaluation of limited knowledge of the history of family forms in Eastern Europe.

As the author states, researchers who analyzed households in historical Poland generally hypothesized the predominance of nuclear households, tentatively assuming the existence of different family systems operating on its eastern peripheries. Since the 1960s, a body of research has been dedicated to the structure of peasant households in Poland, but they were not sufficient to build a comprehensive portrait of family forms in the PLC. Szoltysek declares in the introduction (vol. 1, pp. 4-5) that the book was conceived as a reaction to excessive generalizations based on the Western European experience. He explains that "rethinking" family systems, the aim of the book, means to reconstruct family structures in the forms they originally took on the historical lands of East-Central Europe in a period in which traditional social and demographic patterns still had a considerable degree of permanence.

The analysis starts from one of the richest collections of historical data on European population living in pre-industrial rural settings, a database called CEURFAMFORM, derived from various types of nominative listings of individuals by residential units, covering territories of 12 subregions of the vast PLC territory. The CEURFAMFORM

(c) The Author(s). 2019 Open Access This article is distributed under the terms of the Creative Commons Attribution 4.0 International License (http://creativecommons.org/licenses/by/4.0/), which permits unrestricted use, distribution, and reproduction in any medium provided you give appropriate credit to the original author(s) and the source, provide a link to the Creative Commons license, and indicate if changes were made. 
database is the most extensive database of its type in Polish historical demography, and it represents the largest research-driven data collection for the history of peasant living arrangements in East-Central Europe; its organization consents to move between several levels of aggregation of the data. The database includes data for more than 26,000 peasant households (about 156,000 people) from historical Poland-Lithuania, belonging to over 230 parishes and almost 1000 settlements.

To ensure that the collection was relatively homogeneous in terms of social, environmental, and cultural factors, the population enumerations for cities and towns were excluded. In addition, the listings of Jewish populations were excluded too. This study is therefore a research on the history of "ordinary people," illiterate groups of rural people enumerated in the censuses. The 12 subregions of the PLC territory were selected by grouping parishes and estates on the basis of their administrative affiliation. Moreover, taking into account the existence of their regularities and similarities in the patterns of family organization, the regions have been grouped into four macroregions (clusters) to facilitate comparative discussion of the findings.

At its period of maximum expansion, the PLC incorporated areas that at present are included in the modern nation-states of Poland, Lithuania, Latvia, Russia, Belarus, Ukraine, and Moldova. The book gives details (Appendix I in vol. 2) about the quality of the available sources and their limitations, referring to the standardization of microdata, their comparability, and the appropriate level of aggregation. The solution of the various problems implies that the CEURFAMFORM database is constantly being supplemented and corrected.

The ethnic and religious diversity found in this dataset is particularly interesting. In the different regions of the PLC, the coexistence of Polish, Belarusians, Ukrainians, and German communities was common, as well as the coexistence (or the preponderance) of Protestant and Roman Catholic communities.

The area had then a wide variety of languages, religions, and cultures, as well as heterogeneous ecological and traditional environments. Szoltysek starts (vol. 1, p. 4) from this heterogeneity to discuss one of the central tenets of sociological and historical studies of the family that has long postulated "...the existence of a specific, peculiar 'eastern European type' of domestic group organization. Its inherent features - i.e., complex family organization, early and universal marriage, and familistic societal values - were presumed to transcend physical, political, and cultural boundaries in sustaining a common family model across the vast territory of Eastern Europe". In effect, this simplicistic view of historical family behavior in Eastern Europe has persisted among Western researchers, impeding the awareness of variation within these regions.

The author recalls the research lines proposed by P. Laslett, R. Wall, and by the early Cambridge Group in the study on households, family systems, and demographic impacts on household kin composition in historical populations. In particular, he discusses about the "Hajnal line"; at first, his motivation for the research has been represented by Hajnalian and post-Hajnalian assumptions-useful to provide an interpretive starting point for the studies on family organization-but these perspectives do not represent the unique classifying framework of this research.

Not only a demographic perspective but also sociological and anthropological perspectives are often utilized in various interpretive sections of the book; given the multidisciplinary nature of the research, a multiplicity of methodologies to analyze various 
aspects of family systems is applied. The application of quantitative methods includes this book in the tradition of historical demography approaches. Indeed, the analysis of the database is done with attention to issues very familiar to all researchers in the field of family history: the age of leaving home, life-cycle servitude, nuptiality, household formation, and domestic group structure and living arrangements. Issues are all related to "the family," a crucial element of society for the definition of age and sex roles, kinship, socialization, and for the transmission of values.

The first volume-divided into two parts-comprises some large sections coping with the major topics. The first part (Contexts) contains an introduction to East-Central Europe, the discussion of the historical, socio-economic, and cultural background of the analyzed area, the presentation of previous studies, and the introduction to a re-conceptualization of Eastern European family pattern. In the following pages, a detailed introduction to the CEURFAMFORM database includes its scope, content, and structure as well as the presentation of the methods employed in this research. The first part ends with the delineation of the basic parameters of demographic diversity of the investigated regions.

The second part of the volume is devoted to the main life course events; from chapter 6 to chapter 9 , the study of life course events analyzes the sequence leaving home-marriage-household formation. Chapter 6 analyses the timing, spread, and prevalence of home-leaving processes across major zones of Poland-Lithuania, looking at the variability in the distribution of the ages at leaving the parental home, and discusses the observed variation between clusters and regions. In chapter 7 , a variety of quantitative methodologies has been employed to investigate the incidence and the demographic characteristics of peasant domestic service in historical Polish territories covered by the CEURFAMFORM database. In the Polish territories, service was a central destination stage of home-leavers, and the research aimed at describing the demographic characteristics of individuals who performed service, as well as the function of service as a life-course stage between leaving home and marriage and household formation in different familial and demographic contexts. Chapters 8 and 9 are devoted to marriage and family formation to explain the most important elements of the PolishLithuanian nuptiality patterns and the types of postnuptial living arrangements. The analysis starts from the timing (the age at marriage) and quantity (the proportion who never marry) of nuptiality to reveal the variation in both the timing and the incidence of marriage between and within regional populations of historical Poland-Lithuania. Chapter 10, where domestic group structure and living arrangements are analyzed, represents the obvious culmination of all of the former analyses. Szoltysek uses a range of complementary classification schemes to better capture the relationships between the different entities included in the database and to reveal in greater depth the living arrangement patterns. An interesting depth study pertains to the propensities of elderly people to live in complex family arrangements, carried on using empirical data and microsimulation. As microdata derive from cross-sectional census, computer microsimulation was implemented in order to see whether certain coresidential patterns might be affected by purely demographic constraints.

The volume ends with extended general conclusions, focusing on the discussion about the "diversity" of family forms in the various regions of the European continent, most particularly in the east-central zone. 
The complexity of the book, the analysis, and the findings' vastness, make it extremely difficult to have a synthesis of the interesting results. In the different steps of the analysis, numerous quantitative measurements have been applied to capture patterns of leaving home (or not leaving it); work, that involved various "servant" statuses; marriage; household formation; and domestic group structures and living arrangements among 12 regions of Poland-Lithuania. On the one hand, it emerged that the survival strategies and family patterns adopted by the rural families of this extensive territory at the end of the eighteenth century were similar to those adopted by their counterparts in other European regions. On the other hand, findings showed that the regional variation in political economy and ecology overlapped quite precisely with different patterns of family organization, indicating the existence of (three) region-specific historical family systems. Considerable numerical and qualitative differences emerged among these systems with respect to home-leaving patterns, the timing of marriage, household formation, and multi-generational coresidence. The results of these life-cycle dynamics in the PLC confirmed that in Eastern Europe, they varied by locality and region. The results on the individual zones lead Sztolysek to propose "...to attempts at a mechanical re-positioning of the famous Hajnal line" (p. 782, vol 1).

The research can represent a pillar in historical demographic studies, but in the concluding remarks, Sztolyse states that findings are not yet fully satisfactory. The author proposes to integrate the results of the analysis of the diversification of family forms on Polish-Lithuanian lands with other investigations on East-Central European historical similarities and differences. For example, the vast land between Germany and Russia remains open for further investigation.

Abbreviation

PLC: Polish-Lithuanian Commonwealth

Acknowledgements

Not applicable

Funding

I did not receive any funding for this publication.

Availability of data and materials

Not applicable (book review)

Author's contributions

The author read and approved the final manuscript.

Competing interests

The author declares that she has no competing interest.

Publisher's Note

Springer Nature remains neutral with regard to jurisdictional claims in published maps and institutional affiliations.

Received: 26 November 2018 Accepted: 27 November 2018

Published online: 17 January 2019 